\title{
Identification and characterization of new designer drug 4-fluoro-PV9 and $\alpha$-PHP in the seized materials
}

\author{
Milena Majchrzak ${ }^{1,3}$ - Marcin Rojkiewicz ${ }^{2,3} \cdot$ Rafał Celiński $^{3} \cdot$ Piotr Kuś $^{2}$ • \\ Mieczysław Sajewicz ${ }^{1}$
}

Received: 12 August 2015/Accepted: 21 September 2015/Published online: 13 October 2015

(C) The Author(s) 2015. This article is published with open access at Springerlink.com

\begin{abstract}
In this study, we present identification and physicochemical characterization of new cathinone derivatives, 4-fluoro-PV9 and already known $\alpha$-PHP in seized materials. Although the disclosure of $\alpha$-PHP from an illegal product had been reported and characterized to some extent, the data on $\alpha$-PHP are also presented together with those of 4-fluoro-PV9. The data of characterization for the two compounds were obtained by high-performance liquid chromatography (HPLC)-mass spectrometry and HPLCdiode array detection, electrospray ionization/ion trap mass spectrometry in $\mathrm{MS}^{2}$ and $\mathrm{MS}^{3}$ modes, gas chromatography-mass spectrometry, thermogravimetric analysis, differential scanning calorimetry, Fourier transform infrared spectroscopy, ultraviolet-visible spectroscopy, and nuclear magnetic resonance spectroscopy. To our knowledge, this is the first report for identification and detailed characterization of 4-fluoro-PV9 circulated on the illegal drug market.
\end{abstract}

Keywords Designer drugs - 4-Fluoro-PV9 - $\alpha$-PHP . ESI-MS/MS · GC-MS · NMR

Marcin Rojkiewicz

marcin.rojkiewicz@us.edu.pl

1 Department of General Chemistry and Chromatography, Institute of Chemistry, University of Silesia, 9 Szkolna Street, 40-006 Katowice, Poland

2 Department of Organic Synthesis, Institute of Chemistry, University of Silesia, 9 Szkolna Street, 40-006 Katowice, Poland

3 Toxicology Laboratory ToxLab, 6 Kossutha Street, 40-844 Katowice, Poland

\section{Introduction}

In the global market of designer drugs, new products continuously appear that contain already known psychoactive compounds and mixtures thereof, but also new compounds, not yet characterized in any way [1-3]. According to the European Early Warning System, in Europe in 2005 alone, 14 novel psychoactive compounds were identified, and in 2013 the number of such compounds grew to over 80 items $[1,4]$. Striking features are a wide spectrum of the marketed compounds and the forms in which they are traded. In Poland, consumables containing psychoactive ingredients are currently marketed as "fireplace kindling", "bidet refreshers", "humidity adsorbents", "driver's charms", or "leech tamers". Among the substances seized on the Polish and European Union drug market, derivatives of piperazine and phenylethylamine are frequently found, along with the synthetic cannabinoids, but the most frequently identified group is that of the cathinone derivatives [1-3, 5-11].

Synthetic analogs of cathinone can be divided into four groups; i.e., those containing $\mathrm{N}$-alkyl- or alkyl/halogen substituents in any given position of the aromatic ring, those with methylenedioxy-substituted structures also in any given position of the aromatic ring, those with a pyrrolidinyl group at the nitrogen atom, and those with combined substituents of the second and the third groups [12-16]. Among the most frequently identified cathinones distributed on the Polish market, one can find 3-MMC (2-(methylamino)-1-(3-methylphenyl)-1-propanone), pentedrone (2-(methylamino)-1-phenyl-1-pentanone), 4-MEC (2-(ethylamino)-1-(4-methylphenyl)-1-propanone), MDPV (3,4-methylenodioxypyrovalerone), $\alpha$-PVP (1-phenyl-2-(1pyrrolidinyl)-1-pentanone), and MDPBP (3,4-methylenodioxy- $\alpha$-pyrrolidinobutiophenone) [17-21]. 
Due to an increasing number of designer drugs available on the drug market and taking into account the vital possibility of synthesizing and manufacturing structural modifications of already known psychoactive substances, the availability of analytical characteristics of these compounds is inevitable for their efficient and rapid identification $[8,18,22-26]$. In this study, we present, for the first time to our knowledge, analytical characteristics of 4-fluoro-PV9 (1-(4-fluorophenyl)-2-(pyrrolidin-1-yl)octan-1one) in seized materials. Although we could detect $\alpha$-PHP (1-phenyl-2-(1-pyrrolidinyl)-1-hexanone) from another seized material, its disclosure from an illegal product had been reported by Uchiyama et al. [27].

We mainly present and discuss relevant analytical data obtained for 4-fluoro-PV9 and $\alpha$-PHP by high-performance liquid chromatography-mass spectrometry (HPLC-MS) and high-performance liquid chromatography-diode array detection (HPLC-DAD), ion trap mass spectrometry with electrospray ionization (ESI) in the $\mathrm{MS}^{2}$ and $\mathrm{MS}^{3}$ modes, gas chromatography-mass spectrometry (GC-MS), thermogravimetric analysis (TGA), differential scanning calorimetry (DSC), Fourier transform infrared (FTIR) spectroscopy, ultraviolet-visible (UV-VIS) spectroscopy and proton and carbon nuclear magnetic resonance spectroscopy ( ${ }^{1} \mathrm{H}$ NMR and ${ }^{13} \mathrm{C}$ NMR).

\section{Materials and methods}

\section{Chemicals}

In our study, all reagents used were of the HPLC and MS purity grade. Water (Chromasolv), methanol, acetonitrile, $0.1 \mathrm{M}$ formic acid and ammonium formate were purchased from Sigma-Aldrich, Poznan, Poland. For the NMR analysis, deuterated chloroform $\left(\mathrm{CDCl}_{3}\right)$, also purchased from Sigma-Aldrich, was used.

\section{Sample preparation}

The analyzed samples were seized by the police in 2014 in the Silesia region of South Poland and delivered to our laboratory for toxicological examination. Both samples were obtained in powdered form. Sample no. 1 was crumbled pale pink powder, and sample no. 2 was lumped beige powder.

For the purpose of liquid and gas chromatography, 10-mg aliquots of each powder were weighted, dissolved in $1 \mathrm{~mL}$ of acetonitrile/methanol $(50: 50, v / v)$ mixture, and ultrasonicated for $10 \mathrm{~min}$. From each solution, $10 \mu \mathrm{L}$ were collected and diluted with $990 \mu \mathrm{L}$ methanol. Finally, the extracts were ready for analysis. For NMR spectroscopic analysis, $10 \mathrm{mg}$ of each sample was dissolved in $0.6 \mathrm{~mL} \mathrm{CDCl}_{3}$ and analyzed. For the purpose of FTIR, a 2-mg aliquot of each sample was taken and mixed with $\mathrm{KBr}$, and pellets were formed. The $\mathrm{KBr}$ pellets were analyzed. For the purpose of TGA, DSC and UVVIS spectroscopy, a 5-mg aliquot of each sample was taken for analysis. The TGA and DSC analysis were performed without any further sample treatment, and for the UV-VIS analysis, the samples were dissolved in methanol.

\section{HPLC-MS and HPLC-DAD conditions}

In our investigations, the high-performance liquid chromatograph Thermo Surveyor coupled with the mass spectrometer Thermo LCQ DecaXP-Plus with an electrospray ionization source (Thermo Scientific, Warsaw, Poland) was used. The obtained data were processed with use of the Xcalibur and LCQTune programs (Thermo Scientific).

For the HPLC-MS analysis, the Hypersil RP C18 column $(150 \times 4.6 \mathrm{~mm})$ (Thermo Scientific) was used and analysis was carried out in gradient mode. Mobile phase was composed of solvent A $(0.02 \mathrm{M}$ water solution of formic acid/0.05 $\mathrm{M}$ water solution of ammonium formate) and solvent B (10\% solvent A/90\% acetonitrile), and the following gradient program was applied: $0-2 \mathrm{~min}, 95 \%$ (A) $+5 \% \quad(\mathrm{~B}) ; \quad 2-30 \mathrm{~min}, \quad 30 \% \quad(\mathrm{~A})+70 \% \quad$ (B); 30-32 min, $30 \%$ (A) + $70 \%$ (B); 32-40 min, the solvent ratio was returned to the initial state, i.e., $95 \%(\mathrm{~A})+5 \%$ (B). The mobile phase flow rate was $100 \mu \mathrm{L} \mathrm{min}{ }^{-1}$.

The analytes were electrosprayed in the positive mode (ESI(+)-MS). Fragmentation in the ESI-MS ${ }^{2}$ and ESI-MS ${ }^{3}$ mode was carried out in the scanning range of $m / z 50-500$. The source temperature was $250^{\circ} \mathrm{C}$, and the carrier and ionizing gases were nitrogen and helium, respectively.

\section{GC-MS analysis}

For GC-MS analysis, the Thermo Trace Ultra chromatograph was used, coupled with the Thermo DSQ mass spectrometer (Thermo Scientific). The analyses were carried out with use of the Rxi ${ }^{\circledR}-5$ Sil MS column (Restek, Bellefonte, PA, USA). The following working parameters were employed: injector temperature, $260^{\circ} \mathrm{C}$; oven temperatures, $100{ }^{\circ} \mathrm{C}$ for $2 \mathrm{~min}$, ramp at $20{ }^{\circ} \mathrm{C} \mathrm{min}^{-1}$ to $260{ }^{\circ} \mathrm{C}$; carrier gas (helium) flow rate, $1.2 \mathrm{~mL} \mathrm{~min}^{-1}$; MS transfer line temperature, $250{ }^{\circ} \mathrm{C}$; MS source temperature, $250{ }^{\circ} \mathrm{C}$; injection volume, $1 \mu \mathrm{L}$, on splitless mode.

The obtained electron ionization (EI) mass spectra were compared to those of an EI-MS library [28] for structural confirmation.

\section{NMR spectroscopy}

The NMR spectra were recorded with use of the UltraShield $400 \mathrm{MHz}$ apparatus (Bruker, Bremen, Germany). Deutered chloroform was used as solvent. 

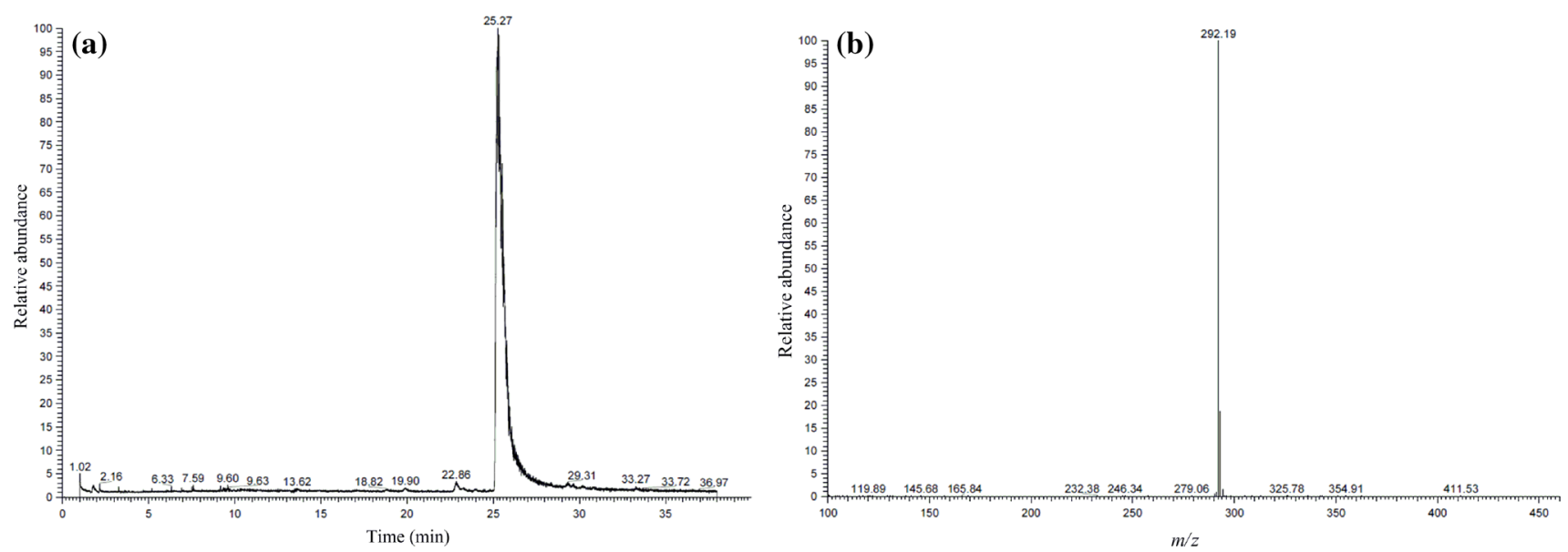

Fig. 1 a Total ion current chromatogram (TIC) and $\mathbf{b}$ the single-stage mass spectrum of the intense peak appearing in the TIC obtained from the compound in sample no. 1, recorded by high-performance liquid chromatography-mass spectrometry (HPLC-MS)

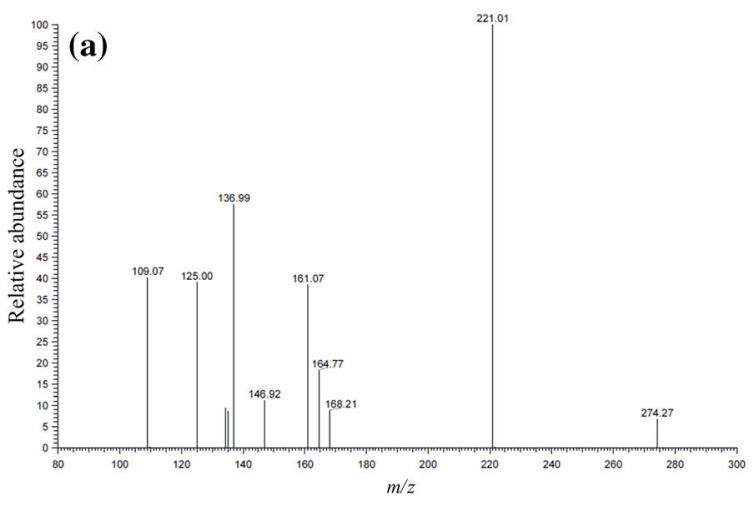

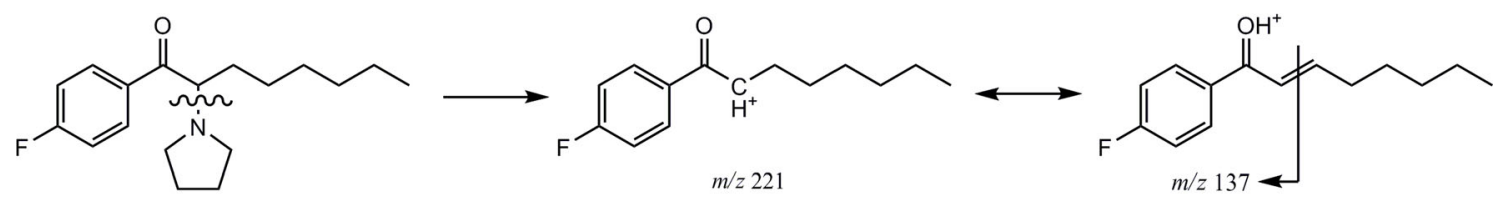

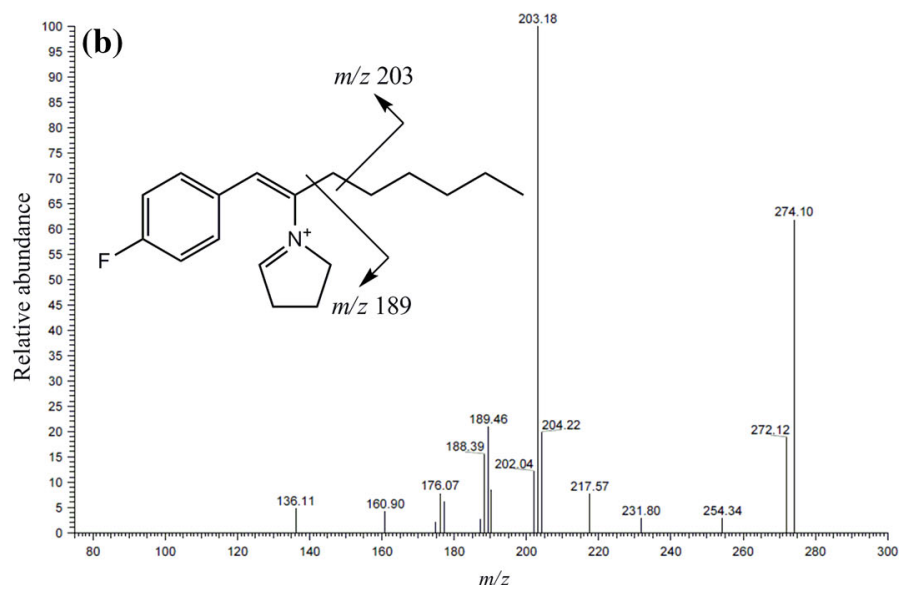

Fig. 2 Product ion mass spectra obtained by ion trap mass spectrometry (MS) in the a MS ${ }^{2}$ (tandem) and $\mathbf{b} \mathrm{MS}^{3}$ modes for sample no. 1 . The precursor ions used for the $\mathrm{MS}^{2}$ and $\mathrm{MS}^{3}$ modes were those at $\mathrm{m} / z, 292$ and 274, respectively 
Fig. 3 Mass spectrum of the compound contained in sample no. 1 , obtained by gas chromatography-mass spectrometry (GC-MS) in the electron ionization $(\mathrm{EI})$ mode

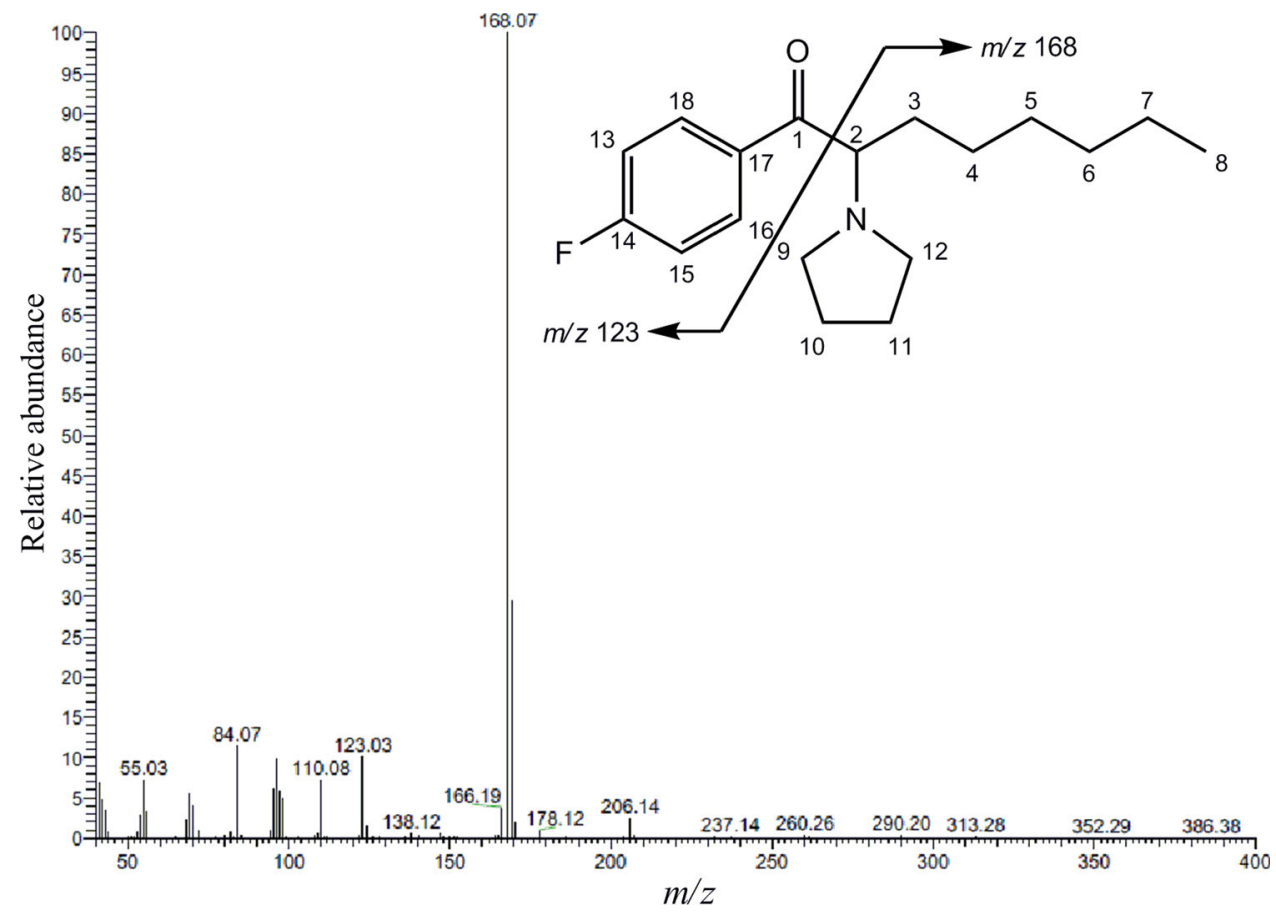

Table $1{ }^{1} \mathrm{H}$ and ${ }^{13} \mathrm{C}$ nuclear magnetic resonance (NMR) data for sample no. 1

\begin{tabular}{lll}
\hline $\begin{array}{l}\text { Carbon atom } \\
\text { position }\end{array}$ & $\begin{array}{l}\text { Carbon chemical } \\
\text { shifts }(\mathrm{ppm})\end{array}$ & $\begin{array}{l}\text { Proton chemical } \\
\text { shifts }(\mathrm{ppm})\end{array}$ \\
\hline 1 & 195.20 & - \\
2 & 64.87 & $5.50(\mathrm{dt}, 1 \mathrm{H})$ \\
3 & 31.13 & $2.08(\mathrm{~m}, 2 \mathrm{H})$ \\
$4,5,6,7$ & $30.82 ; 29.11 ;$ & $1.15-1.35(\mathrm{~m}, 8 \mathrm{H})$ \\
& $25.52 ; 22.36$ & $0.79(\mathrm{t}, 3 \mathrm{H})$ \\
8 & 13.85 & $3.12(\mathrm{~m}, 1 \mathrm{H}) ;$ \\
9 & 52.72 & $3.86(\mathrm{~m}, 1 \mathrm{H})$ \\
& & $2.18(\mathrm{~m}, 4 \mathrm{H})$ \\
10,11 & $23.85 ; 23.66$ & $3.69(\mathrm{~m}, 2 \mathrm{H})$ \\
12 & 51.23 & $7.22(\mathrm{~m}, 2 \mathrm{H})$ \\
13,15 & $116.51 ; 116.53$ & - \\
14 & $165.53 ; 168.10$ & $8.13(\mathrm{~m}, 2 \mathrm{H})$ \\
16,18 & $131.88 ; 131.93 ; 131.96$ & - \\
17 & 131.79 & \\
\hline
\end{tabular}

The carbon atom numbering is shown in Fig. 4a

\section{Thermogravimetric analysis (TGA) and differential scanning calorimetry (DSC)}

TGA was carried out with use of the TGA/DSC1 MettlerToledo thermal analyzer (Mettler-Toledo, Greifensee, Switzerland), with a heating rate of $10{ }^{\circ} \mathrm{C} / \mathrm{min}$ in a stream of nitrogen $\left(60 \mathrm{~cm}^{3} \mathrm{~min}^{-1}\right)$. DSC was performed with a
TA-DSC 2010 apparatus (TA Instruments, New Castle, DE, USA) under nitrogen using aluminum sample pans. The DSC experiments were carried out in a nitrogen atmosphere with a temperature range from $-70{ }^{\circ} \mathrm{C}$ to over the clearing point.

\section{Fourier transform infrared and UV-VIS spectroscopy}

The infrared (IR) spectra were acquired with use of the PerkinElmer Spectrum One spectrometer (PerkinElmer, Waltham, MA, USA) using the $\mathrm{KBr}$ pellets. The UV-VIS absorption spectra were recorded in the methanol solution using the PerkinElmer Lambda Bio 40 UV-VIS spectrometer.

\section{Results and discussion}

\section{Identification of the compound contained in sample no. 1}

Upon analysis of sample no. 1 by HPLC-MS, the total ion current (TIC) chromatogram (Fig. 1a) showed an intense peak at $25.27 \mathrm{~min}$. Otherwise, no marked peaks appeared, showing that sample no. 1 contained almost a single compound with high purity (probably more than $95 \%$ ). Figure $1 \mathrm{~b}$ shows the HPLC-MS spectrum of the intense peak observed in Fig. 1a; a base peak appeared at $m / z 292$. Because this peak seemed to be protonated molecular one 
<smiles>CCCCCCC(C(=O)c1ccc(F)cc1)N1CCCC1</smiles><smiles>CCCCC(C(=O)c1ccccc1)N1CCCC1</smiles>

Fig. 4 Target compound structures with carbon atom numbering for nuclear magnetic resonance analysis. a The compound contained in the sample no. $1 ; \mathbf{b}$ the compound contained in sample no. 2

$\left[\mathrm{M}+\mathrm{H}^{+}\right]$, the unknown compound may have a molecular weight of $291 \mathrm{Da}$. In the product ion mass spectra in the $\mathrm{MS}^{2}$ (tandem) mode using the peak at $\mathrm{m} / \mathrm{z} 292$ as the precursor ion, a peak at $\mathrm{m} / \mathrm{z}, 274$ appeared (Fig. 2a), which indicated the elimination of one water molecule from the protonated molecular ion $\left[\mathrm{M}+\mathrm{H}-\mathrm{H}_{2} \mathrm{O}\right]^{+}$. This transformation is a well-known characteristic of cathinone derivatives. Given that this compound is assumed to be one of the cathinone derivatives, the product ion mass spectrum in the $\mathrm{MS}^{3}$ mode using the peak at $m / z 274$ as the precursor ion, which neither includes a carbonyl nor hydroxyl group, showed a base peak at $\mathrm{m} / \mathrm{z} 203$ and a fragment peak at $\mathrm{m} / \mathrm{z}$
189 (Fig. 2b), suggesting that the cathinone derivative has pyrrolidinyl and fluorophenyl moieties in its structure. The appearance of the base peak at $m / z, 221$ in Fig. 2a is easily explicable by removal of the pyrrolidinyl moiety from the molecule.

Unfortunately, in this study, we did not use the highresolution MS that can give a molecular formula. Instead, we compared the GC-EI-MS spectra to those of an EI-MS spectral library, and fortunately, the EI-MS spectrum obtained from sample no. 1 matched well with that of 4-fluoro-PV9, which had very recently been added to the library. In both spectra, the peak at $m / z, 168$ appeared as the base peak; the fragment peaks at $m / z 169,123,110,95,84$ and 55 appeared to be in common (Fig. 3).

Therefore, it seemed correct that the compound contained in sample no. 1 was fluoro-PV9, but the question of which position of the phenyl ring the fluorine atom was attached remained unclear, because it is well known that such regioisomers give the same or very similar EI-mass spectra.

To finally determine the position of the fluorine atom in the aromatic ring, the NMR spectrum was recorded, as shown in Table 1 . The carbon numbering is shown in Fig. 4a.

As a result, confirmation of the anticipated structure was obtained. Namely, in the aromatic range of the ${ }^{1} \mathrm{H}$ NMR spectrum, two signal groups appeared, and witnessed to the presence of the fluorine atom at position para of the phenyl ring. Due to the proton interactions with the fluorine atom, two multiplets were observed instead of a "classical" signal arrangement (i.e., the doublets for each group of equivalent protons). Coupling with the fluorine atom was also visible in the ${ }^{13} \mathrm{C}$ NMR spectrum, where signals originating from carbon atom no. 14, and those from no. 13 and 15 are split to the doublets.
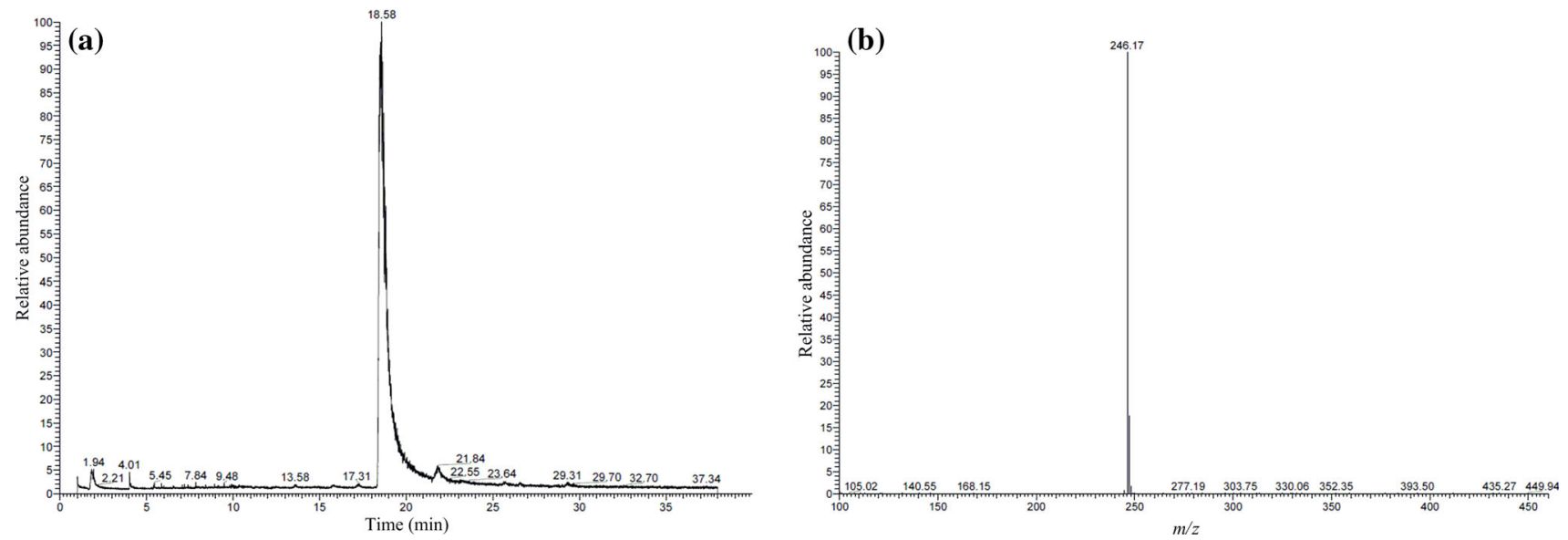

Fig. 5 a TIC and $\mathbf{b}$ the single-stage mass spectrum of the intense peak appearing in the TIC, obtained from the compound in sample no. 2 recorded by HPLC-MS 


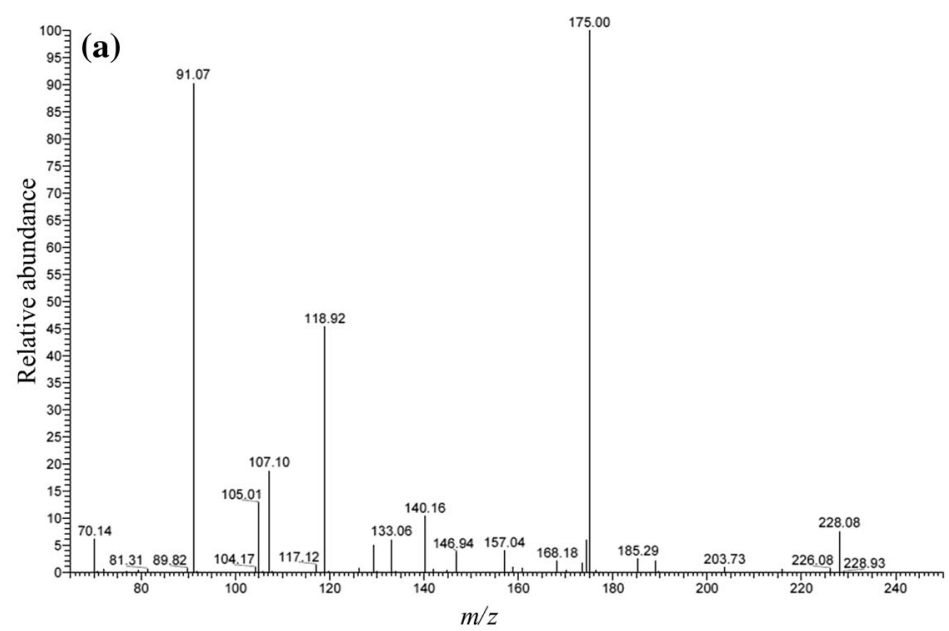

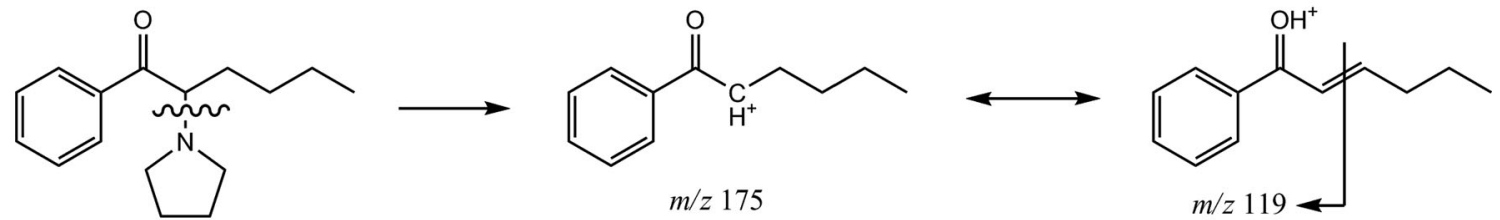
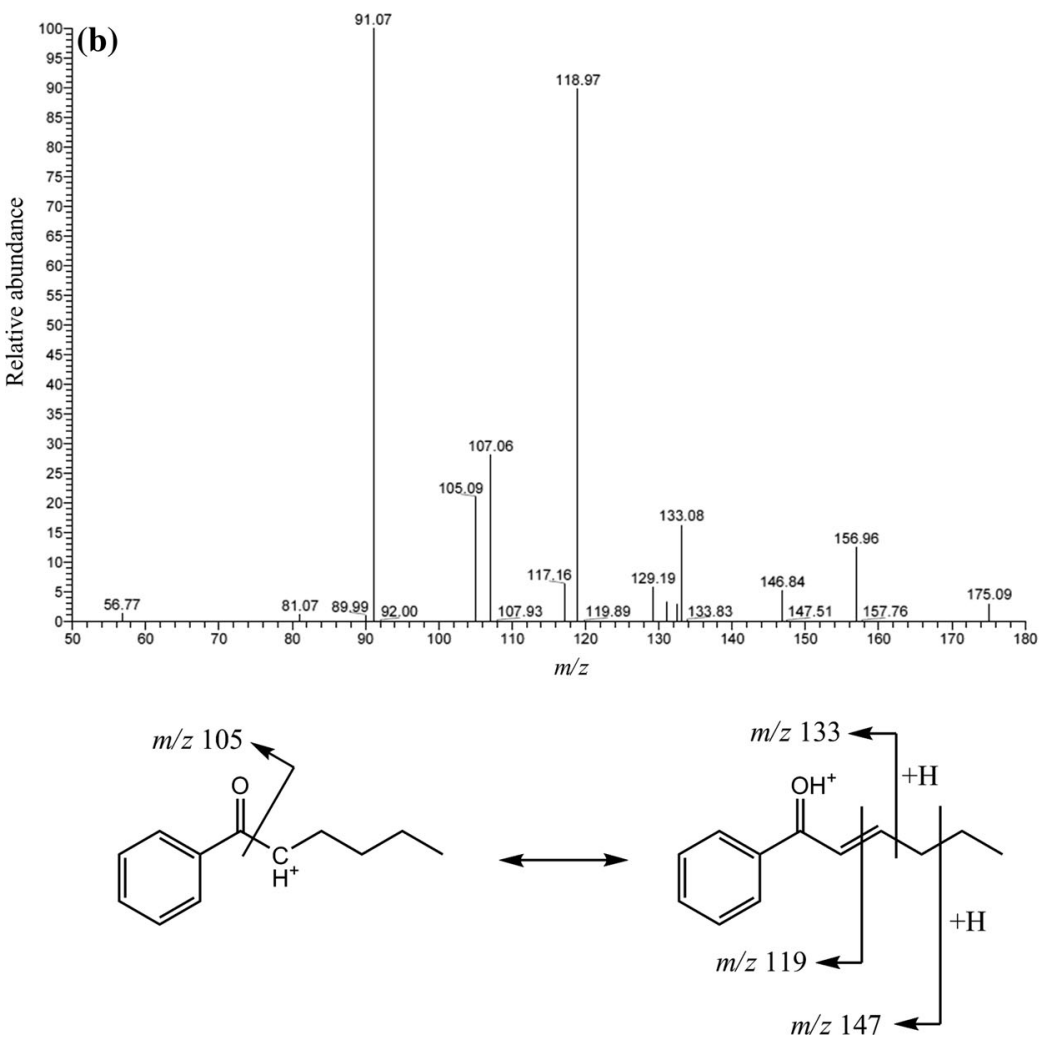

Fig. 6 Product ion mass spectra obtained by ion trap MS in a $\mathrm{MS}^{2}$ (tandem) and $\mathbf{b} \mathrm{MS}^{3}$ modes for sample no. 2. The precursor ions used for the $\mathrm{MS}^{2}$ and $\mathrm{MS}^{3}$ modes were those at $\mathrm{m} / z, 246$ and 175, respectively

Due to the fact that sample no. 1 appeared as a hydrochloride, in the ${ }^{1} \mathrm{H}$ NMR spectrum, a signal is observed at $11.95 \mathrm{ppm}$, originating from the proton of the quaternary pyrrolidine group. Therefore, it can be concluded that the compound contained in sample no. 1 is 4-fluoro-PV9 (1-(4-fluorophenyl)-2-(pyrrolidin-1-yl)octan1-one). To our knowledge, this is the first report to identify 4-fluoro-PV9 in an authentic seizure sample. 
Fig. 7 Mass spectrum of the compound contained in sample no. 2, obtained by GC-MS in the EI mode

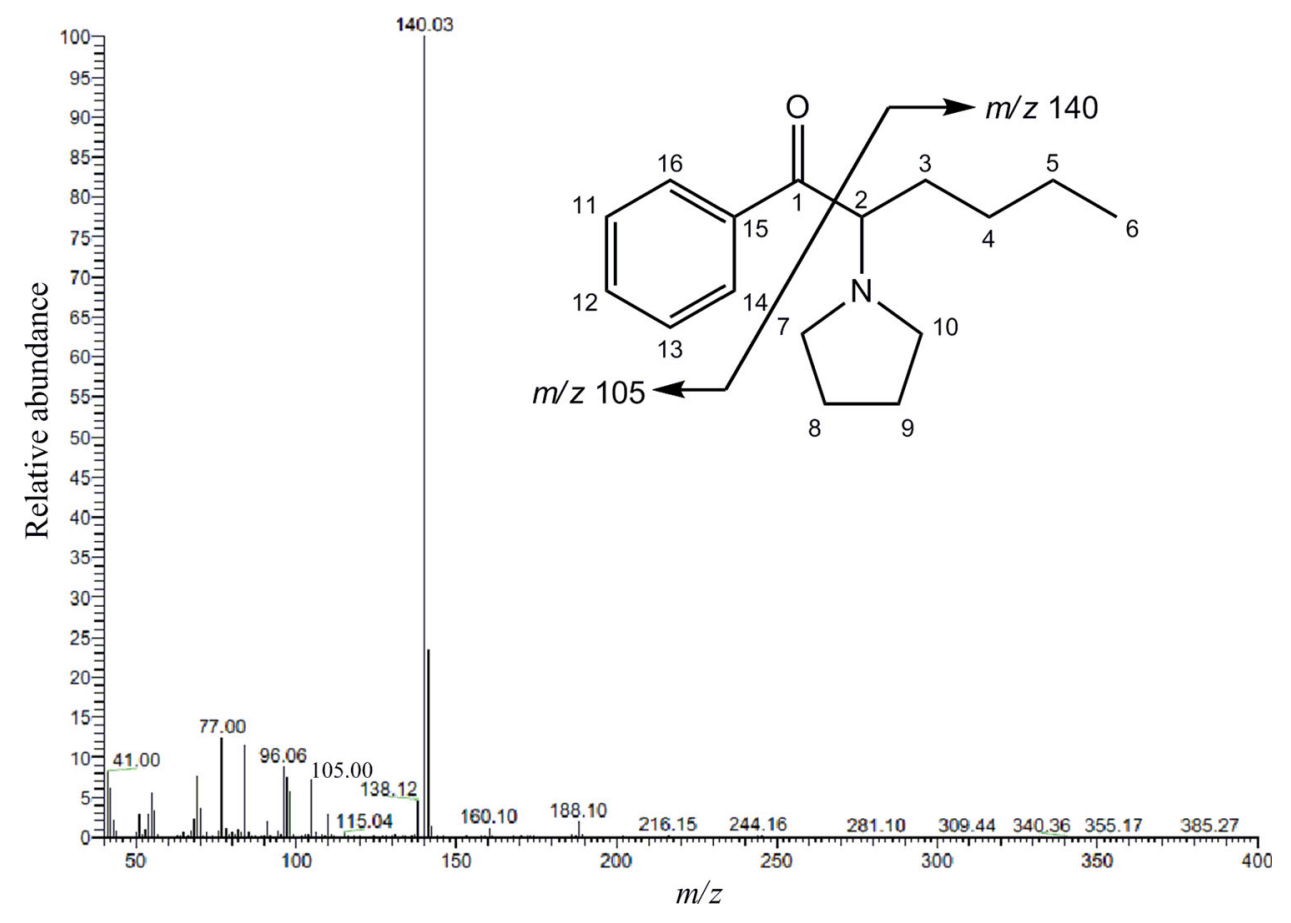

Table $2{ }^{1} \mathrm{H}$ and ${ }^{13} \mathrm{C}$ NMR data for sample no. 2

\begin{tabular}{lll}
\hline $\begin{array}{l}\text { Carbon atom } \\
\text { position }\end{array}$ & $\begin{array}{l}\text { Carbon chemical } \\
\text { shifts }(\mathrm{ppm})\end{array}$ & $\begin{array}{l}\text { Proton chemical } \\
\text { shifts }(\mathrm{ppm})\end{array}$ \\
\hline 1 & 196.78 & - \\
2 & 62.87 & $5.15(\mathrm{dt}, 1 \mathrm{H})$ \\
3 & 30.62 & $2.03(\mathrm{~m}, 2 \mathrm{H})$ \\
4,5 & $27.93 ; 22.50$ & $1.33(\mathrm{~m}, 4 \mathrm{H})$ \\
6 & 13.48 & $0.84(\mathrm{t}, 3 \mathrm{H})$ \\
7 & 52.90 & $2.83(\mathrm{~m}, 1 \mathrm{H}) ; 3.68(\mathrm{~m}, 1 \mathrm{H})$ \\
8,9 & $23.93 ; 23.71$ & $2.21(\mathrm{~m}, 4 \mathrm{H})$ \\
10 & 49.51 & $3.84(\mathrm{~m}, 2 \mathrm{H})$ \\
11,13 & 129.43 & $7.58(\mathrm{t}, 2 \mathrm{H})$ \\
12 & 135.16 & $7.73(\mathrm{t}, 1 \mathrm{H})$ \\
14,16 & 128.62 & $7.98(\mathrm{~d}, 2 \mathrm{H})$ \\
15 & 135.75 & - \\
\hline
\end{tabular}

The carbon atom numbering is shown in Fig. $4 \mathrm{~b}$

\section{Identification of the compound contained in sample no. 2}

Upon analysis of sample no. 2 by HPLC-MS, the TIC (Fig. 5a) showed an intense peak at $18.58 \mathrm{~min}$. Otherwise, no marked peaks appeared, showing that sample no. 2 contained almost a single compound with high purity. Figure $5 b$ shows the HPLC-MS spectrum of the intense peak observed in Fig. 5a; a base peak appeared at $m / z 246$.
In the product ion mass spectrum in the $\mathrm{MS}^{2}$ mode (Fig. 6a), the peak due to elimination of one water molecule at $\mathrm{m} / \mathrm{z} 228$ also appeared, suggesting that the compound is also a cathinone derivative, and the peak due to the elimination of the pyrrolidinyl moiety appeared as the base peak at $m / z 175$. The product ion mass spectrum in the $\mathrm{MS}^{3}$ mode was also recorded using the ion at $\mathrm{m} / \mathrm{z} 175$ as the precursor ion for further analysis of the probable structure (Fig. 6b).

Figure 7 shows the GC-MS spectrum of the compound in sample no. 2, and it was compared to that described in the library [28]. The EI-mass spectrum obtained from sample no. 2 was well matched that of $\alpha$-PHP (1-phenyl-2(1-pyrrolidinyl)-1-hexanone). In both spectra, the peak at $\mathrm{m} / \mathrm{z} 140$ appeared as the base peak; the fragment peaks at $m / z, 141,105,96$ and 77 appeared in common.

As shown in Table 2, the data from ${ }^{1} \mathrm{H}$ NMR and ${ }^{13} \mathrm{C}$ NMR analysis of sample no. 2 confirmed the presence of $\alpha$ PHP (the carbon numbering is shown in Fig. 4b). Similar to sample no. 1 , the compound in sample no. 2 was also present in the hydrochloride form, which resulted in the appearance of a signal at $12.65 \mathrm{ppm}$ originating from the proton of the quaternary pyrrolidine group.

It should be mentioned that Uchiyama et al. [27] reported the identification of $\alpha$-PHP in an illegal product in 2014; they reported GC-MS mass spectrum, UV spectrum and ${ }^{1} \mathrm{H}$ NMR and ${ }^{13} \mathrm{C}$ NMR for $\alpha$-PHP, which generally agree with the data described in this study. 

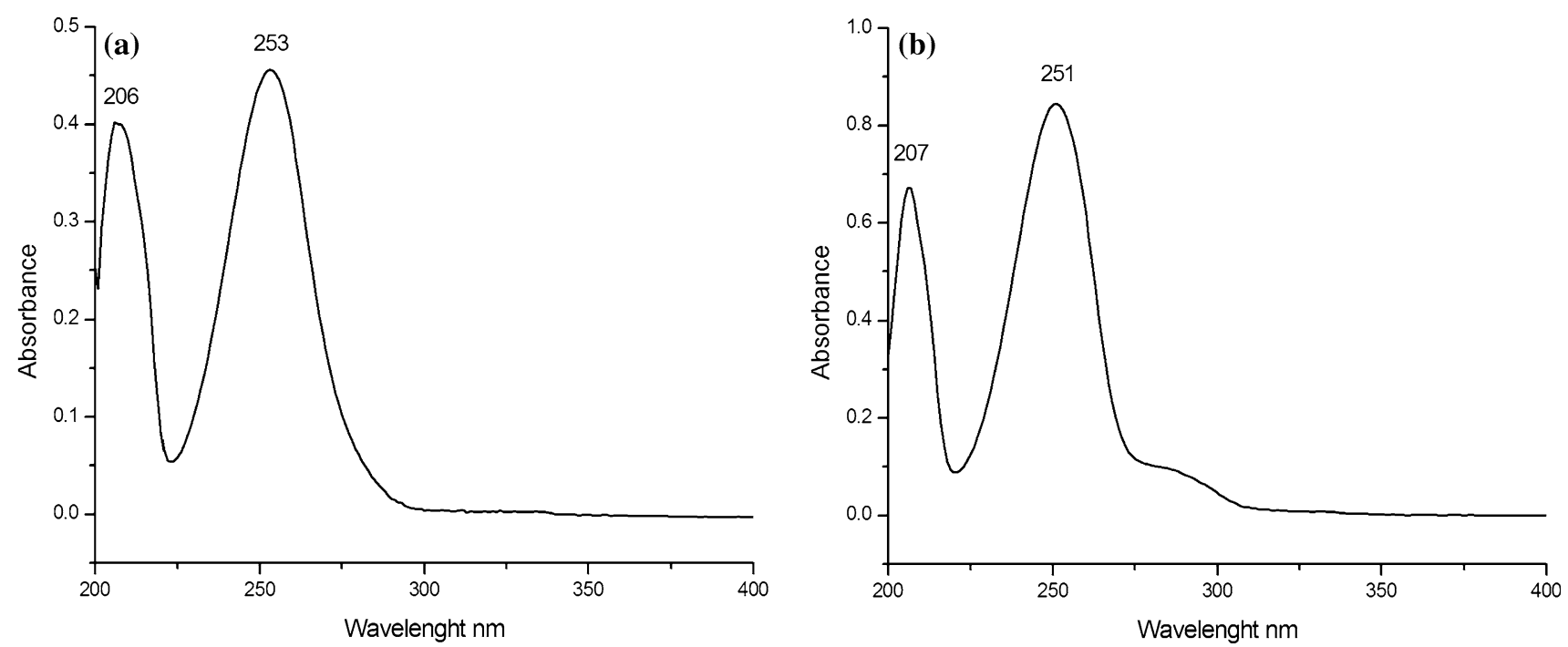

Fig. 8 Ultraviolet-visible spectroscopy for the compounds contained in a sample no. 1 and $\mathbf{b}$ sample no. 2
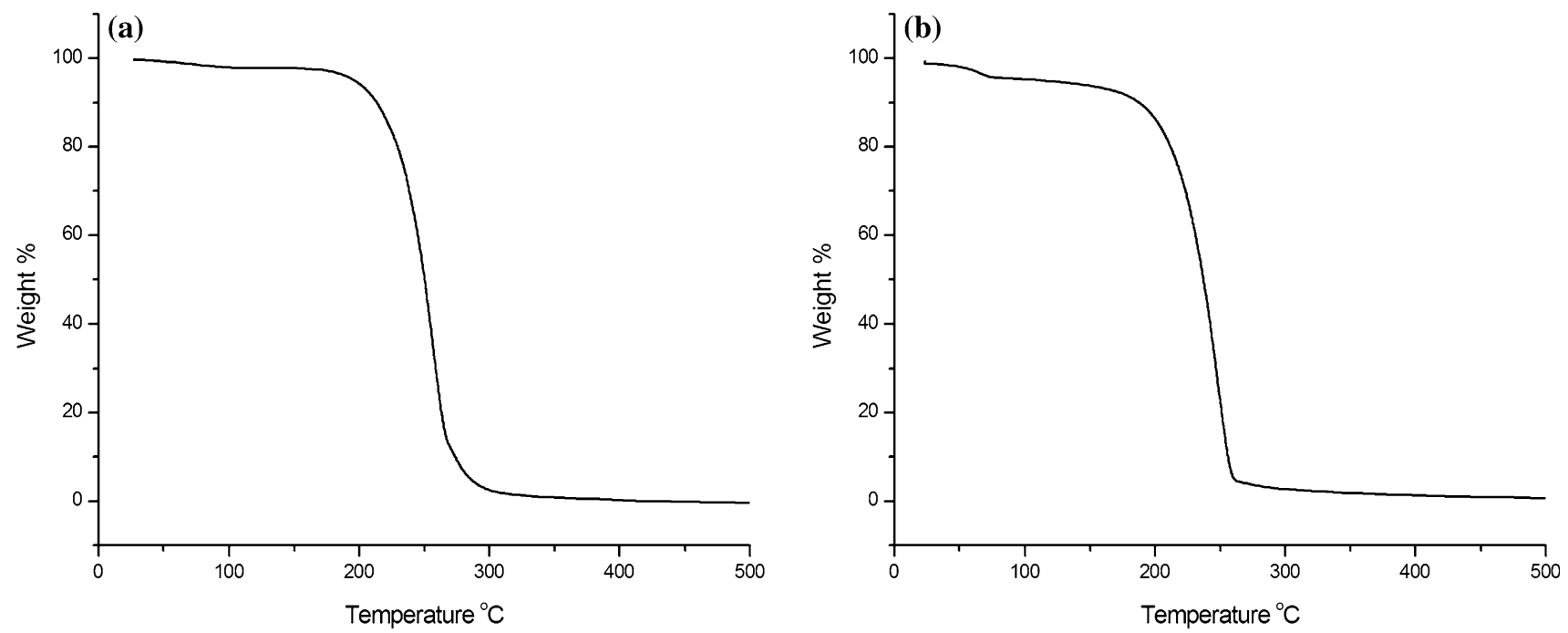

Fig. 9 Thermogravimetric spectra for the compounds contained in a sample no. 1 and b sample no. 2

\section{Other physicochemical analytical results for 4- fluoro-PV9 and $\alpha$-PHP identified in this study}

The UV spectra recorded by HPLC-DAD and UV-VIS spectrometry showed absorption maxima at 254 and $253 \mathrm{~nm}$, respectively, for the compound in sample no. 1 (4fluoro-PV9); they were 252 and $251 \mathrm{~nm}$, respectively, for that in sample no. 2 ( $\alpha$-PHP) (Fig. 8). The symmetrical peaks and the absence of impurity peaks in the spectra show that each compound existed in the materials in high purity.

The TGA spectra for both compounds are shown in Fig. 9a, b, respectively. Both spectra showed single main transitions corresponding to their decomposition. The decomposition temperatures for those in sample no. 1 and sample no. 2 were 259 and $250{ }^{\circ} \mathrm{C}$, respectively. The only one main transition observed for each compound shows that the purity of each compound was high.

By DSC analysis, melting points for the compounds in the samples no. 1 and no. 2 were 144 and $65^{\circ} \mathrm{C}$, respectively; those measured in the classic way were 140-142 and $62-64{ }^{\circ} \mathrm{C}$, respectively.

By the FTIR spectroscopy, a strong carbonyl stretch at $1685 \mathrm{~cm}^{-1}$, the aliphatic $\mathrm{CH}$ stretching at $2800-3000 \mathrm{~cm}^{-1}$ and the amine hydrochloride salt bands at $2476-2752 \mathrm{~cm}^{-1}$ were observed for the compound in the sample no. 1; a strong carbonyl stretch at $1678 \mathrm{~cm}^{-1}$, the aliphatic $\mathrm{CH}$ stretching at $2800-3000 \mathrm{~cm}^{-1}$ and the amine hydrochloride salt bands at $2494-2750 \mathrm{~cm}^{-1}$ were observed for the compound in sample no. 2. Due to the structural similarity of 
both compounds, their IR spectra were very similar, as described above.

\section{Conclusions}

In this study, we experienced the analysis of compounds in two seized materials. We used various analytical tools for their identification and characterization, such as HPLCMS, HPLC-DAD, ion trap MS in $\mathrm{MS}^{2}$ and $\mathrm{MS}^{3}$ modes, GC-MS, TGA, DSC, FTIR spectroscopy, UV-VIS spectroscopy and ${ }^{1} \mathrm{H}$ and ${ }^{13} \mathrm{C}$ NMR spectroscopy. The compounds contained in sample no. 1 and no. 2 were found to be 4-fluoro-PV9 and $\alpha$-PHP, respectively. Although $\alpha$-PHP had been identified and characterized to some extent in 2014, to our knowledge, this is the first report on the identification and characterization of 4-fluoro-PV9. The data presented in this article will be useful for forensic toxicologists who are alert to the emergence of new psychotropic drugs.

\section{Compliance with ethical standards}

Conflict of interest The authors have no financial or other relations that could lead to a conflict of interest.

Ethical approval This article does not contain any studies with human participants or animals performed by any of the authors.

Open Access This article is distributed under the terms of the Creative Commons Attribution 4.0 International License (http://crea tivecommons.org/licenses/by/4.0/), which permits unrestricted use, distribution, and reproduction in any medium, provided you give appropriate credit to the original author(s) and the source, provide a link to the Creative Commons license, and indicate if changes were made.

\section{References}

1. Liechti M (2015) Novel psychoactive substances (designer drugs): overview and pharmacology of modulators of monoamine signaling. Swiss Med Wkly 145:w14043

2. Baumann MH, Solis E, Watterson LR, Marusich JA, Fantegrossi WE, Wiley JL (2014) Bath salts, spice, and related designer drugs: the science behind the headlines. J Neurosci 34:15150-15158

3. Weaver MF, Hopper JA, Gunderson EW (2015) Designer drugs 2015: assessment and management. Addict Sci Clin Pract. doi:10. 1186/s13722-015-0024-7

4. European Monitoring Centre for Drugs and Drug Addiction (2015) New psychoactive substances in Europe. Publications Office of the European Union, Luxembourg (An update from the EU Early Warning System)

5. Arbo MD, Bastos ML, Carmo HF (2012) Piperazine compounds as drugs of abuse. Drug Alcohol Depen 122:174-185

6. Schep LJ, Slaughter RJ, Vale JA, Beasley DMG, Gee P (2011) The clinical toxicology of the designer "party pills" benzylpiperazine and trifluoromethylphenylpiperazine. Clin Toxicol 49:131-141
7. Srisuma S, Bronstein AC, Hoyte CO (2015) NBOMe and 2C substitute phenylethylamine exposures reported to the National Poison Data System. Clin Toxicol 53:624-628

8. Zuba D, Sekuła K, Buczek A (2013) 25C-NBOMe-new potent hallucinogenic substance identified on the drug market. Forensic Sci Int 227:7-14

9. Denooz R, Vanheugen JC, Frederich M, de Tullio P, Charlier C (2013) Identification and structural elucidation of four cannabimimetic compounds (RCS-4, AM-2201, JWH-203 and JWH-210) in seized products. J Anal Toxicol 37:56-63

10. Adamowicz P, Lechowicz W (2015) The influence of synthetic cannabinoid UR-144 on human psychomotor performance-a case report demonstrating road traffic risks. Traffic Inj Prev. doi:10.1080/15389588.2015.1018990

11. Katz DP, Bhattacharya D, Bhattacharya S, Deruiter J, Clark CR, Suppiramaniam V, Dhanasekaran M (2014) Synthetic cathinones: "a khat and mouse game". Toxicol Lett 229:349-356

12. Valente MJ, Guedes de Pinho P, de Lourdes Bastos M, Carvalho F, Carvalho M (2014) Khat and synthetic cathinones: a review. Arch Toxicol 88:15-45

13. Szendrei K (1980) The chemistry of khat. Bull Narc 32:5-35

14. Patel NB (2015) "Natural amphetamine" khat: a cultural tradition or a drug of abuse? Int Rev Neurobiol 120:235-255

15. Brenneisen R, Fisch HU, Koelbing U, Geisshüsler S, Kalix P (1990) Amphetamine-like effects in humans of the khat alkaloid cathinone. Br J Clin Pharmacol 30:825-828

16. Vardakou I, Pistos C, Spiliopoulou C (2011) Drugs for youth via Internet and the example of mephedrone. Toxicol Lett 201:191-195

17. Gibbons S, Zloh M (2010) An analysis of the "legal high" mephedrone. Bioorg Med Chem Lett 20:4135-4139

18. Westphal F, Junge T, Klein B, Fritschi G, Girreser U (2011) Spectroscopic characterization of 3,4-methylenedioxypyrrolidinobutyrophenone: a new designer drug with $\alpha$-pyrrolidinophenone structure. Forensic Sci Int 209:126-132

19. Kaizaki A, Tanaka S, Numazawa S (2014) New recreational drug 1-phenyl-2-(1-pyrrolidinyl)-1-pentanone (alpha-PVP) activates central nervous system via dopaminergic neuron. J Toxicol Sci 39:1-6

20. Uralets V, Rana S, Morgan S, Ross W (2014) Testing for designer stimulants: metabolic profiles of 16 synthetic cathinones excreted free in human urine. J Anal Toxicol 38:233-241

21. Jankovics P, Váradi A, Tölgyesi L, Lohner S, Németh-Palotás J, Koszegi-Szalai H (2011) Identification and characterization of the new designer drug 4'-methylethcathinone (4-MEC) and elaboration of a novel liquid chromatography-tandem mass spectrometry (LC-MS/MS) screening method for seven different methcathinone analogs. Forensic Sci Int 210:213-220

22. Ibáñez M, Sancho JV, Bijlsma L, Van Nuijs ALN, Covaci A, Hernández F (2014) Comprehensive analytical strategies based on high-resolution time-of-flight mass spectrometry to identify new psychoactive substances. Trac-Trend Anal Chem 57:107-117

23. Uchiyama N, Matsuda S, Kawamura M, Shimokawa Y, KikuraHanajiri R, Aritake K, Urade Y, Goda Y (2014) Characterization of four new designer drugs, 5-chloro-NNEI, NNEI indazole analog, $\alpha$-PHPP and $\alpha$-POP, with 11 newly distributed designer drugs in illegal products. Forensic Sci Int 243:1-13

24. Fornal E (2013) Identification of substituted cathinones: 3,4methylenedioxy derivatives by high performance liquid chromatography-quadrupole time of flight mass spectrometry. J Pharm Biomed Anal 81-82:13-19

25. Zuba D (2012) Identification of cathinones and other active components of "legal highs" by mass spectrometric methods. Trac-Trend Anal Chem 32:15-30

26. Westphal F, Junge T, Rösner P, Fritschi G, Klein B, Girreser U (2007) Mass spectral and NMR spectral data of two new designer drugs with an $\alpha$-aminophenone structure: $4^{\prime}$-methyl- $\alpha$ - 
pyrrolidinohexanophenone and $4^{\prime}$-methyl- $\alpha$-pyrrolidinobutyrophenone. Forensic Sci Int 169:32-42

27. Uchiyama N, Shimokawa Y, Kawamura M, Kikura-Hanajiri R, Hakamatsuka $\mathrm{T}$ (2014) Chemical analysis of a benzofuran derivative, 2-(2-ethylaminopropyl)benzofuran (2-EAPB), eight synthetic cannabinoids, five cathinone derivatives, and five other designer drugs newly detected in illegal products. Forensic Toxicol 32:266-281

28. Cayman Chemical (2015) Cayman spectral library. https://www. caymanchem.com/app/template/SpectralLibrary.vm. Accessed 6 Mar 2015 